\title{
desafios nO ATENDIMENTO A MULHERES COM RISCO E/OU TENTATIVA DE SUICIDIO EM UMA MATERNIDADE DE ALTO RISCO
}

\author{
Challenges of care of women at risk and/or \\ attempting suicide in a high-risk maternity
}

Larissa Bastos ${ }^{1}$, Silvana Maria Escorsim² ${ }^{2}$, Maria Cristina Dias de Lima ${ }^{3}$, Nattany Caruline Santos Rodrigues ${ }^{4}$

1. Assistente Social Residente do Programa de Residência Integrada Multiprofissional em Atenção Hospitalar - PRIMAH do CHC/UFPR. Bacharela em Serviço Social pela UFPR. Email: larissabastos. jc@gmail.com. ORCID: https://orcid.org/0000-0001-5412-4912.

2. Professora Adjunta do curso de Serviço Social da UFPR Litoral, doutora em Serviço Social pela PUC - São Paulo, tutora do Eixo Profissional de Serviço Social do PRIMAH - CHC/UFPR na área profissional de Serviço Social. Email: mariaescorsim@uol.com.br. ORCID: https://orcid.org/00000002-4240-1692

3. Assistente Social do CHC/UFPR, Coordenadora do Eixo Profissional de Serviço Social do PRIMAH CHC/UFPR, mestre em Saúde Coletiva pela UFPR. Email: mariacrissllima@gmail.com. ORCID: https:// orcid.org/0000-0002-2044-0439.

4. Assistente Social do CHC/UFPR, preceptora na área de Serviço Social no Programa de Saúde da Mulher do PRIMAH - CHC/UFPR, especialista em Saúde da Mulher pelo CHC/UFPR. Email: nattanyrodrigues@gmail.com ORCID: https://orcid.org/0000-0001-6859-9441.

CONTATO: Larissa Bastos | Endereço: Rua Luiz Antonio Amatuzzi de Pinho, nº 1010, Casa 5 | Jardim Paranaguá | Paranaguá, Paraná, Brasil | CEP: 83.215-170 | Telefone: (41) 98533- 5616 / (41) 3424-2489 | E-mail: larissabastos.jc@gmail.com

COMO CITAR: Bastos L, Escorsim SM, Lima MCD, Rodrigues NCS. Desafios no atendimento a mulheres com risco e/ou tentativa de suicídio em uma maternidade de alto risco. R. Saúde Públ. 2019 Jul;2(1):43-56. 
RESUMO Segundo a Organização Mundial da Saúde - OMS (2014), o suicídio é um grave problema de saúde pública. Esta pesquisa empenhou-se em analisar a ação profissional no atendimento a mulheres com risco e/ou tentativa de suicídio numa maternidade de alto risco do sul do Brasil. Estudo descritivo e quanti - qualitativo, com 20 profissionais de saúde de diversas áreas. Os dados foram coletados durante entrevista com cada profissional, utilizando questionário semiestruturado e pesquisa documental com as Fichas de Notificação de Violência Autoprovocada e registros internos do Serviço Social do local pesquisado. Os resultados revelam dificuldades nos atendimentos, relacionadas às condições e relações de trabalho, bem como a lacunas na formação profissional referentes à temática do suicídio. Devido à complexidade do tema, ratifica-se a necessidade de revisão da organização do trabalho para esses atendimentos no local e qualificação desses profissionais referente à temática, visto que instituir mudanças requer profissionais capacitados e qualificados.

PALAVRAS-CHAVES: Saúde pública. Suicídio. Mulheres. Tentativa de Suicídio.

ABSTRACT According to the World Health Organization - WHO (2014), suicide is a serious public health problem. This research focused on analyzing professional action in the care of women at risk and/or attempting suicide in a high-risk maternity hospital in the south of Brazil. This is a descriptive, quantitative and qualitative study with 20 health professionals from different health areas. Data were collected during interviews with each professional, using a semi-structured questionnaire and documentary research with the Self-Injury Report Sheets and internal records of the Social Service of the place researched. The results reveal difficulties in attendance, related to working conditions and relationships, as well as gaps in professional training related to suicide. Due to the complexity of the theme, the need for a review of the work organization for these on-site care, and the qualification of these professionals regarding the subject is enhanced, since making changes requires trained and qualified professionals.

KEYWORDS: Public health. Suicide. Women. Suicide Attempted.

\section{INTRODUÇÃO}

7

ste estudo tem como objetivo analisar a ação profissional no atendimento às mulheres com risco e/ou tentativa de suicídio na Unidade Materno Infantil - UMI do Complexo Hospital de Clínicas - CHC/UFPR. O interesse em realizar a pesquisa surgiu a partir da experiência proporcionada pelo Programa de Residência Integrada Multiprofissional em Atenção Hospitalar PRIMAH do CHC/UFPR, no eixo de Saúde da Mulher, onde foram realizadas observações e intervenções a diversas demandas, dentre elas, o atendimento a mulheres com risco e/ou tentativa de suicídio. 
No cotidiano de trabalho da UMI essa demanda é frequente e foram observadas empiricamente dificuldades e/ou despreparo pelos profissionais da equipe de saúde, frente a isso. Tais dificuldades se apresentavam durante o acolhimento, atendimento e encaminhamento dessas situações.

O suicídio tem sido incorporado ao conceito de violência e, conforme preconizado pela Organização Mundial da Saúde - OMS1', a violência autoprovocada é subdividida em: comportamento suicida e autoagressão, sendo que o primeiro inclui pensamentos suicidas, tentativas de suicídio e suicídios propriamente ditos, e a autoagressão inclui atos como a automutilação. A OMS² afirma que o suicídio é um grave problema de saúde pública, que atinge os diversos grupos da sociedade a nível mundial.

O comportamento suicida e a autoagressão são fenômenos complexos e multicausais, e possuem como determinantes: fatores sociais, econômicos, culturais, psicológicos, biológicos e a história de vida pessoal. Ter acesso aos meios de cometer suicídio, apresentar dificuldade em lidar com estresses agudos ou crônicos da vida, e sofrer violência baseada em gênero, abuso sexual infantil ou discriminação correspondem a fatores de risco para o suicídio. ${ }^{3.4 .5 .6}$ A presença de transtornos mentais, uso de álcool e outras drogas, histórico de lesões autoprovocadas e tentativas de suicídio, são apontados como os fatores de risco mais importantes para novas tentativas. ${ }^{7.8,6}$

Devido à complexidade do tema, foi utilizado nesta pesquisa o termo "risco e/ou tentativa de suicídio", para designar vários aspectos que envolvem o ato suicida, entendendo que apenas o termo suicídio não contempla todos os fenômenos que chegam ao local pesquisado. Portanto, para fins deste estudo, entende-se como risco de suicídio situações que envolvem: ideação suicida; automutilação; uso de álcool e outras drogas; transtornos mentais; tentativas de suicídio prévias e/ou tentativa de suicídio atual; histórico de comportamento suicida no núcleo familiar; vítimas de violência doméstica e/ou sexual, entre outras.

As últimas estatísticas referentes aos óbitos por suicídio no Brasil, apresentadas no Boletim Epidemiológico da Secretaria Nacional de Vigilância em Saúde ${ }^{6}$, apontaram um aumento de 209\% de casos notificados de tentativa de suicídio por mulheres no país. No Paraná, conforme o Sistema de Informação de Agravos de Notificação - SINAN ${ }^{9}$ entre os anos de 2010 e 2015, dos 5.583 casos de violência autoprovocada notificados, 3.829 ocorreram por pessoas do sexo feminino, ou seja, quase $70 \%$ dos casos notificados.

A forma de morrer é algo cultural, então, cada cultura e sociedade vivenciam a morte não intencional e o suicídio de formas diferentes e, historicamente, existe estigma e tabu em torno desse tema, que podem comprometer o cuidado. Buscar ajuda nessas situações por evitar mortes, porém o estigma impede a procura pela mesma. ${ }^{6.10}$ Estudos afirmam que os contextos hospitalares têm sido considerados um lócus privilegiado para refletir sobre o cuidado em saúde no Sistema Único de Saúde - SUS, bem como que o mesmo é necessariamente multidisciplinar e multiprofissional. ${ }^{4}$

Diante disso, refletir sobre a ação profissional empregada no atendimento às mulheres com risco e/ou tentativa de suicídio torna-se essencial para promover melhorias e contribuir para o fomento de pesquisa na área. Sendo assim, este artigo se propõe a refletir sobre alguns aspectos do processo de trabalho em saúde no atendimento às mulheres atendidas com risco e/ou tentativa de suicídio na UMI - CHC/UFPR. Logo, pretende-se, com este estudo, contribuir para a produção de estratégias de prevenção e práticas de cuidado em saúde acerca do comportamento suicida.

\section{METODOLOGIA}

Estudo descritivo e de caráter quanti- 
qualitativo, com dois momentos de coleta de dados, desenvolvido na Unidade Materno Infantil - UMI do CHC/UFPR, onde foram entrevistados 20 profissionais de diferentes formações na área da saúde, dos quais: médicos, psicólogos, enfermeiros, assistentes sociais, terapeutas ocupacionais, técnicos(as) de enfermagem e auxiliares de enfermagem. Os critérios de inclusão foram a experiência no atendimento a mulheres com risco e/ou tentativa de suicídio. 0 instrumento utilizado para coleta dos dados qualitativos tratou-se de um roteiro de entrevistas composto por 10 questões semiestruturadas. Tais questões investigavam a prática profissional dos participantes, desde o acolhimento, as rotinas de atendimento e encaminhamentos realizados, com questões que contemplavam ainda a atuação profissional, tempo de trabalho na instituição, conhecimento científico sobre a temática do suicídio e condições de trabalho.

Para a coleta de dados quantitativos, foram utilizadas as Fichas de Notificação de Violência Autoprovocada, referentes a mulheres com risco e/ou tentativa de suicídio, bem como registros internos da equipe de Serviço Social da UMI, considerando o período de janeiro de 2016 a janeiro de 2018, a fim de identificar as situações envolvendo mulheres com risco e/ou tentativa de suicídio no local pesquisado. A coleta de ambos os dados ocorreu entre os meses de agosto e outubro de 2018. As Fichas de Notificação Individual de Violência Interpessoal/Autoprovocada foram disponibilizadas pelo Serviço de Epidemiologia Hospitalar - SEPIH/Unidade de Vigilância em Saúde - UVS do CHC/UFPR, mediante relatório. Os livros de registros internos do Serviço Social da UMI foram concedidos pela equipe. Os dados da pesquisa documental foram submetidos à leitura sistemática e análise descritiva.

As entrevistas foram transcritas e os dados foram analisados a partir da análise de conteúdo de Bardin..1" A construção das categorias de análise aconteceu a posteriori, à medida que estas foram emergindo do texto durante a etapa de leitura flutuante e sendo inter ligadas às subcategorias, que por sua vez chegaram a um maior nível de codificação e desmembramento analógico, representado pelos elementos de análise. No que concerne às questões éti cas, esta pesquisa foi submetida ao Comitê de Ética em Pesquisa com Seres Humanos (CEP/HC/UFPR) e foi aprovada em julho de 2018 (parecer $n^{\circ}$ 2.760.486, de 08/07/2018).

\section{RESULTADOS E DISCUSSÃO}

Conforme os dados coletados a partir da leitura sistemática dos livros de registros internos do Serviço Social da UMI, foram encontrados 31 atendimentos a mulheres com risco e/ou tentativa de suicídio, sendo que: 18 eram gestantes, 7 eram puérperas e 6 foram atendidas pelo Serviço de Atendimento às Vítimas de Violência Sexual que inclui mulheres que buscam o serviço por estarem gestantes decorrente de estupro -, 8 mulheres possuíam histórico de uso de substâncias psicoativas - SPA, 9 possuíam diagnóstico de transtorno mental e 1 possuía ambos.

Esses dados apresentam quantidade significativa de gestantes com risco e/ou tentativa de suicídio (cerca de 60\%), bem como o uso de SPA (26\%), os transtornos mentais (29\%) e a soma de ambos (4\%). Esses resultados vão de encontro com documentos e indicadores internacionais sobre a temática. De acordo com o documento Prevención del Suicidio - OMS², entre 25\% e 50\% dos casos de suicídio havia, concomitantemente, uso de álcool e outras substâncias. Consoante com o estudo epidemiológico realizado na Inglaterra, ${ }^{12}$ o suicídio está entre as principais causas de mortes maternas, acometendo 10\% dessa população e, ainda, conforme o estudo de Barraclough et. al $^{13}$, o comportamento suicida pode atingir até um quarto da população de gestantes.

Quanto aos dados coletados nas Notificações de Violência Autoprovocada, foram analisadas 36 
fichas inerentes aos atendimentos a mulheres com risco e/ou tentativa de suicídio em todo o CHC/UFPR. Dessas, 12 se tratavam de pacientes que haviam sido atendidas na UMI. Ou seja, se compararmos os atendimentos encontrados nos livros de registros do Serviço Social versus as notificações realizadas no mesmo período por mulheres com risco e/ou tentativa de suicídio, constata-se uma lacuna, onde 19 situações não foram notificadas, algo que será pontuado no tópico de Considerações Sobre a Ação Profissional em Saúde.

A partir dos dados coletados das Notificações foi possivel identificar que, de maneira geral, há prevalência de atendimentos a tentativa de suicídio (59\%), que a quantidade de gestantes continua sendo expressiva se comparada ao total de atendimentos (21\%) e que, conforme os indicadores nacionais ${ }^{6}$, o meio de agressão mais prevalecente é o envenenamento/ intoxicação (64\%), bem como correlação com uso de álcool (25\%) e de 56\% dos casos terem ocorrido outras vezes, corroborando com a estatística ${ }^{2}$ de que para cada suicídio, ocorrem pelo menos 20 tentativas anteriores e que o uso de álcool e outras SPAs são fatores de risco importantes. Abaixo, na Tabela 1, é possível verificar estes e outros dados coletados das Notificações:

Tabela 1 Características dos casos de violência autoprovocada segundo as Notificações de Violência Autoprovocada de Janeiro de 2016 a Janeiro de 2018.

\begin{tabular}{|c|c|c|c|}
\hline VARIÁVEIS & CATEGORIAS & FREQUÊNCIA (N =36) & PORCENTAGEM (\%) \\
\hline \multirow{4}{*}{ TIPO DE VIOLÊNCIA } & Tentativa de Suicídio & 21 & $59 \%$ \\
\hline & Ideação Suicida & 6 & $17 \%$ \\
\hline & Ideação Suicida e Homicida & 1 & $3 \%$ \\
\hline & Não coletado & 8 & $21 \%$ \\
\hline \multirow[t]{2}{*}{ PROCEDÊNCIA } & Curitiba & 26 & $72 \%$ \\
\hline & Região Metropolitana & 10 & $28 \%$ \\
\hline \multirow{3}{*}{ SAÚDE MENTAL } & Transtorno Mental & 11 & $31 \%$ \\
\hline & Transtorno de Comportamento & 7 & $19 \%$ \\
\hline & Ocorreu outras vezes & 20 & $56 \%$ \\
\hline \multirow{7}{*}{ MEIO DE AGRESSÃO } & Envenenamento/Intoxicação & 23 & $64 \%$ \\
\hline & Ameaça & 2 & $6 \%$ \\
\hline & Objeto Cortante & 2 & $6 \%$ \\
\hline & Objeto Contundente & 1 & $3 \%$ \\
\hline & Enforcamento & 1 & $3 \%$ \\
\hline & Força Corporal & 1 & $3 \%$ \\
\hline & Outros & 3 & $8 \%$ \\
\hline \multirow[t]{2}{*}{ OUTROS } & Gestante & 8 & $21 \%$ \\
\hline & Uso de Álcool & 9 & $25 \%$ \\
\hline
\end{tabular}

Fonte: Elaborado pelos autores (2018). Dados disponibilizados pelo Serviço de Epidemiologia Hospitalar -

SEPIH do Complexo Hospital de Clínicas - CHC/UFPR. 
Por conseguinte, este estudo evidenciou que as situações envolvendo risco e/ou tentativa de suicídio na UMI - CHC/UFPR corroboram com indicadores e escritos nacionais e internacionais sobre a problemática, tratando-se de uma demanda que necessita da atenção da gestão local, a fim de ponderar possibilidades de melhorias nos atendimentos, bem como estratégias de prevenção do suicídio e promoção da saúde das mulheres com risco e/ou tentativa de suicídio, atendidas na UMI. Afinal, os hospitais gerais integram a Rede de Atenção Psicossocial - RAPS, e devem estar preparados para atender questões de saúde mental e ainda:

A atenção aos casos de tentativa de suicídio pressupõe a mobilização e a organização dos serviços de saúde, a partir da construção de linhas de cuidado, da sensibilização dos profissionais e da desestigmatização do problema, da definição de fluxos e responsabilidades, articulados numa rede de cuidados e de proteção envolvendo tanto a saúde quanto recursos e estratégias intersetoriais ${ }^{6}$.

Tabela 2 Síntese das Categorias, Subcategorias e Elementos de Análise.

\begin{tabular}{|c|c|c|}
\hline $\begin{array}{l}\text { SINTESE DAS } \\
\text { CATEGORIAS }\end{array}$ & SUBCATEGORIAS & ELEMENTOS DE ANÁLISE \\
\hline & $\begin{array}{l}\text { Dificuldades nos } \\
\text { atendimentos }\end{array}$ & $\begin{array}{l}\text { - Modelo compartimentalizado e reducionista de organização } \\
\text { - Ausência de médicos psiquiatras } \\
\text { - Condições de trabalho precárias } \\
\text { - Preenchimento de Notificação de Violência Autoprovocada } \\
\text { - Fragilidades no trabalho multiprofissional } \\
\text { - Inexistência de capacitações sobre a temática }\end{array}$ \\
\hline ação profissional em & $\begin{array}{l}\text { Procedimentos e } \\
\text { Encaminhamentos } \\
\text { realizados }\end{array}$ & $\begin{array}{l}\text { - Avaliação da equipe multiprofissional } \\
\text { - Avaliação Médica } \\
\text { - Rede de Proteção } \\
\text { - Avaliação psiquiátrica/internação em hospitais psiquiátricos } \\
\text { - Notificação de Violência Autoprovocada } \\
\text { - Inexistência de protocolos de assistência }\end{array}$ \\
\hline \multirow{2}{*}{$\begin{array}{l}\text { Diferentes Acepções } \\
\text { sobre o Fenômeno do } \\
\text { Suicidio }\end{array}$} & $\begin{array}{l}\text { Conceito de } \\
\text { Suicídio }\end{array}$ & $\begin{array}{l}\text { - Ausência de conhecimento científico sobre a temática } \\
\text { • Visão negativa sobre a mulher } \\
\text { • Estigmatização e tabu } \\
\text { • Correlação com transtornos mentais e uso de substâncias } \\
\text { psicoativas }\end{array}$ \\
\hline & $\begin{array}{l}\text { Características } \\
\text { relacionadas } \\
\text { ao risco e/ou } \\
\text { tentativa de } \\
\text { suicídio }\end{array}$ & $\begin{array}{l}\text { - Inadequação da demanda ao serviço } \\
\text { - Problemas psiquiátricos/transtornos mentais } \\
\text { • Internamentos psiquiátricos e medicalização } \\
\text { - Intoxicação medicamentosa } \\
\text { • Uso de álcool e outras substâncias } \\
\text { • Várias ocorrências na unidade }\end{array}$ \\
\hline
\end{tabular}

Fonte: Elaborado pelos autores (2018), a partir das verbalizações dos (as) participantes da pesquisa. 
Quanto aos dados coletados nas entrevistas, 20 profissionais participaram da pesquisa, os quais serão identificados a partir de agora como P1, P2, P3... P20. Desses, 18 (dezoito) eram mulheres e 2 (dois) eram homens. O tempo de exercício da profissão no âmbito hospitalar variou entre 9 (nove) meses e 30 (trinta) anos e o tempo de trabalho no CHC/UFPR variou de 8 meses a 26 (vinte e seis) anos. Todos os participantes informaram já ter atendido mulheres com risco e/ou tentativa de suicídio mais de uma vez durante sua vida profissional.

Na análise das verbalizações dos participantes (as quais foram submetidas a correções gramaticais e/ou de concordância), observou-se que ao discorrerem sobre o processo de trabalho no atendimento às mulheres com risco e/ou tentativa de suicídio na UMI, relacionavam diretamente a três aspectos: acolhimento, atendimento e encaminhamentos. No intuito de responder os objetivos deste estudo, foram organizadas duas categorias de análise, cuja a primeira é referente às considerações sobre a ação profissional em saúde e a segunda a respeito das diferentes acepções sobre o fenômeno do suicídio, conforme podem ser observadas na Tabela 2.

\section{CONSIDERAÇÕES SOBRE A AÇÃO PROFISSIONAL EM SAÚDE}

Os modelos assistenciais são compostos por um conjunto de processos de trabalho, de serviços de saúde e situam-se em uma conjuntura socialeconômica-cultural-histórica. O trabalho em saúde está voltado à produção da saúde, a fim de atender às necessidades humanas manifestadas no processo de saúde/doença, tratando-se de um "[...] processo coletivo que não se constitui de modo espontâneo, mas sim está sujeito à intencionalidade da formação de um projeto que precisa ser compartilhado por diferentes profissionais e assumido pela direção da gestão das instituições públicas".14
Essa categoria apresentou dois aspectos principais: dificuldades nos atendimentos e os procedimentos/encaminhamentos realizados. Em relação às dificuldades nos atendimentos, o modelo compartimentalizado de atuação profissional, a ausência de médicos psiquiatras, condições de trabalho precárias, o preenchimento da notificação de violência autoprovocada, fragilidades no trabalho multiprofissional e ausência de capacitações, ficaram evidentes nas narrativas dos participantes, sendo colocadas como principais questões que prejudicam a ação profissional.

Interessante destacar que os participantes, majoritariamente, apontam as dificuldades que são visualizadas no cotidiano do trabalho, pela forma como o trabalho em saúde está organizado. Pontuam que o trabalho se dá de forma segmentada, com cada profissão se restringindo a si mesma. Esses elementos podem ser observados nas narrativas a seguir de P2, P3, P8, P10 e P13:

"Ano passado fiz um atendimento a uma paciente
que tinha tentado suicídio. Ela veio pra cá e tentou
suicídio de novo aqui e eu fui chamada depois da
segunda tentativa. Eu fui fazer o atendimento
com ela [...] mas eu tive que fazer o atendimento
numa sala do Centro Obstétrico, ao lado tinha
um parto acontecendo, enquanto eu conversava
com essa menina sobre a situação extremamente
difícil de vida dela, tinha gritos da mulher que
estava dando à luz, isso não é o ambiente ideal"
(informação verbal participante P2).

"Eu acho que a gente tinha que ter um curso para preencher essa ficha de notificação, porque apesar de serem perguntas fechadas, acaba sendo meio subjetivo, sabe, e a gente não tem, eu não saberia preencher essa ficha de notificação com qualidade. Então... eu acho que além de curso em relação ao tema do suicídio, tinha que ter também sobre notificação" (informação verbal participante P3).

"Os recursos que temos não são suficientes, temos o mínimo e o mínimo de forma bem precária, em termos de equipamentos e profissionais também". (informação verbal participante P8).

"Acho que a principal dificuldade que a gente 
tem é que a gente não tem formação, nem treinamento para lidar com essas pacientes, enquanto a gente não recebe apoio de outras especialidades [...] ajudaria bastante se tivesse pelo menos um plantão de sobreaviso da psiquiatria, para avaliar as pacientes e ajudar nesse internamento inicial" (informação verbal participante P10)

"Ainda temos muita dificuldade de trabalhar a questão multi, muita dificuldade, mesmo com a residência já estando aí há quase 10 anos. Acaba que cada um faz o seu [...] Eu acho que a grande dificuldade que a gente tem ainda é o acionamento da psiquiatria. Primeiro que não podemos fazer, quem tem que fazer é o médico, isso já é a primeira barreira" (informação verbal participante P13).

De acordo com Dias ${ }^{15}$, "os serviços de saúde são parte do sistema produtivo e incorporam e/ou refletem as mudanças que ocorrem no mundo do trabalho, orientadas, na atualidade, predominantemente, pelo modelo econômico neoliberal". As narrativas acima refletem uma ação profissional fragmentada e reducionista, bem como o desinvestimento da gestão Institucional em capacitação e educação permanente em relação à temática do suicídio. Ilustram ainda a precarização das condições de trabalho dos profissionais, onde há falta de profissionais e de materiais de trabalho. Isto pode ser elucidado pela trajetória histórica de organização do trabalho em saúde e das profissões da saúde, inclusive da medicina, a qual é marcada pelo paradigma positivista e pela lógica neoliberal.

O paradigma positivista, na segunda metade do século XIX, e posteriormente a Reestruturação Produtiva, com a emergência do Estado Neoliberal, reconfiguraram o direcionamento da saúde, o que influenciou diretamente na atual configuração das profissões inseridas neste espaço, com o aumento da ênfase nas especialidades e a fragmentação do real e do saber científico. ${ }^{14,15}$ Esta fragmentação impõe limites à ação profissional na saúde e limita a possibilidade de um trabalho multiprofissional, tendo em vista que comportam somente uma visão parcial do processo social sobre o qual se dá a intervenção:

\begin{abstract}
A incorporação tecnológica é orientada pelos padrões do mercado, e não pelas necessidades dos sujeitos, com valorização exagerada dos procedimentos técnicos, desconsiderando as inter-relações entre as pessoas, prevalecendo, assim, o "trabalho morto". Porém, no cotidiano dos serviços, várias dimensões e diferentes atores e interesses se entrecruzam na produção do cuidado: profissionais, gestores, empresários, operadoras, prestadores e os usuários, configurando forças em disputa e a micropolítica do "trabalho vivo"15.
\end{abstract}

Diante disso, evidencia-se que esse tipo de modelo prejudica o cuidado em saúde do indivíduo com risco e/ou tentativa de suicídio, pois inviabiliza a integralidade do cuidado, entendida como "uma ação social que resulta da interação democrática entre os sujeitos no cotidiano de suas práticas, na prestação do cuidado da saúde".16 A integralidade focalizada - saber multiprofissional no seu espaço de atuação - e a integralidade ampliada - articulação dos serviços com a rede assistencial composta por outros serviços ${ }^{17}$, são princípios indiscutíveis para o atendimento aos indivíduos com comportamento suicida, portanto "ao se pensar no enfrentamento do suicídio, é importante considerar as múltiplas determinações envolvidas no fenômeno, e não somente as questões biológicas individuais".

Nesta categoria de análise, ainda destacamse os procedimentos que são realizados nos atendimentos às mulheres com risco e/ou tentativa de suicídio. Na rotina da UMI, as pacientes passam por triagem ou pelo acolhimento com classificação de risco, realizado pela equipe de enfermagem. Posteriormente, as pacientes são atendidas pela equipe médica, que irá realizar os procedimentos e encaminhamentos pertinentes aos cuidados médicos (medicalização, exames clínicos e laboratoriais, etc.). Após passar por essas duas etapas, o restante da equipe multiprofissional (psicologia, serviço social, terapia ocupacional, etc.) possivelmente irá realizar 
o atendimento e conforme cada prática profissional serão realizados os devidos procedimentos e encaminhamentos.

No que diz respeito aos procedimentos e encaminhamentos que fazem parte do atendimento, os participantes ponderaram o fato da equipe não ter um direcionamento referente às intervenções necessárias a essas situações no contexto hospitalar, bem como a ausência de um protocolo ou fluxo de atendimento que inclua o atendimento multiprofissional a essas situações, implicando muitas vezes no não atendimento as pacientes e/ ou discordâncias quanto às intervenções realizadas ou não. Como por exemplo, o preenchimento da notificação de violência autoprovocada e encaminhamentos para a rede municipal de atenção psicossocial. Essas questões ficam evidentes nas narrativas a seguir:

"A maioria chegou dessa forma mesmo, com a equipe não sabendo o que fazer com uma paciente que entrava em surto [...] Acredito que uma ação bem importante seria a disseminação da importância de notificação e do estabelecimento de um fluxograma de trabalho, de um protocolo" (informação verbal participante P8).

"[...] então se você focar em fazer seu trabalho o mais rápido possível, o mais preciso possível, não precisa saber exatamente a história, mas você sabe que você faz parte desse contexto e que você tem que ajudar sendo mais clara, mais objetiva, mais rápida, o máximo que você puder. porque logo depois você tem outro profissional e ele também tem a parte dele para ser feita" (informação verbal participante P18).

"Considerando toda a delicadeza do caso, eu acho que a gente deveria de fato ter um fluxo muito bem delimitado, para que você oriente os profissionais que ou não têm lida com isso, ou têm dificuldade, ou não sabem o que fazer poder ter uma diretriz para encaminhar esses casos [...] eu acho que antes do encaminhamento para a rede externa, a gente tem que primeiro acolher melhor e saber exatamente quem chamar. Então se existir um fluxo você sabe o que fazer. para quem encaminhar, eu acho que isso ajuda bastante, dá uma diretriz, um suporte profissional, que é bem importante e que a gente não tem aqui dentro" (informação verbal participante P19).

Nas falas acima, fica evidente que o modelo biomédico ainda é hegemônico no processo de trabalho da UMI e que a inexistência de um protocolo que norteie os atendimentos inviabiliza o trabalho em equipe. Tal modelo, que impera nos hospitais ainda hoje, tem sua organização pautada na segmentação dos sujeitos, que são concebidos a partir de suas doenças e, por conseguinte, das especialidades que irão tratá-las. As diferentes profissões, em sua ação profissional em saúde, também reproduzem essa lógica compartimentalizada, atuando apenas de forma restrita. Entretanto, as diversas profissões se entrecruzam num objetivo comum que é o cuidado em saúde, aparentemente segmentado, tendo em vista a lógica da compartimentalização da saúde acima citada:

\begin{abstract}
O trabalho em saúde é sempre realizado por um trabalhador de dimensão coletiva. Não há nenhum perfil de trabalho que dê conta sozinho do mundo das necessidades de saúde, o objeto real do trabalho em saúde. Os trabalhadores universitários, técnicos e auxiliares são fundamentais para que o trabalho de um dê sentido ao trabalho do outro, na direção da verdadeira finalidade do trabalho em saúde: cuidar do usuário, o portador efetivo das necessidades de saúde ${ }^{18}$.
\end{abstract}

A ausência de um protocolo ou fluxo de atendimento compromete tanto a ação profissional, quanto a qualidade da assistência prestada à paciente, visto que os profissionais ficam sem uma orientação mínima do que fazer. Diante do exposto, evidencia-se a necessidade de estabelecimento de um protocolo para organizar e direcionar a ação profissional no atendimento às mulheres com risco e/ou tentativa de suicídio no cotidiano de trabalho da UMI. Reitera-se, ainda, a urgência de um trabalho em equipe multiprofissional, no qual 
as condutas sejam tomadas coletivamente e ocorra a complementação dos saberes das diferentes áreas de conhecimento, conforme Sá et al. "a interdisciplinaridade, somada à articulação com a rede de serviços disponíveis no território, trazem bons indicativos para a oferta de um cuidado integral às pessoas que tentaram suicídio". 19

Em relação às Notificações de Violência Autoprovocada, a partir de uma questão específica nas entrevistas, foi possível quantificar qual o conhecimento que os participantes detêm sobre as mesmas. Dos 20 entrevistados, 25\% referiram já ter preenchido notificação de violência autoprovocada, 40\% conhecem e já preencheram notificação de violência, porém não de violência autoprovocada, 25\% disseram conhecer, mas nunca ter preenchido e $10 \%$ disseram não saber do que se trata. Esses dados mostram que, apesar da notificação compulsória ter sido instituída enquanto lei em 197520, muitos profissionais ainda desconhecem e/ou negligenciam esse procedimento na prática profissional.

Conforme apontado anteriormente, ao cruzar os dados dos registros internos do Serviço Social da UMI com o relatório das notificações de violência, observaram-se disparidades na relação atendimento/notificação. Vale ressaltar que isso pode ter ocorrido por diversos fatores, dentre eles, o desconhecimento da mesma, a dificuldade de preenchimento da ficha de notificação, por não achar que é de sua competência o preenchimento ou pela ausência de capacitações, conforme as narrativas de P1 e P12 a seguir:

"Eu sugeriria que fosse mais divulgada essa questão da notificação, que é uma questão muito séria e que o profissional tem que estar capacitado para estar preenchendo aquilo, para que depois os dados sejam reais, para que não haja subnotificação" (informação verbal participante P1).

"Eu conheço a ficha, sei da necessidade, mas eu nunca preenchi por não trabalhar como médico assistente do hospital" (informação verbal participante P12).
A Portaria $n^{0}$ 1.271/2014 21 institui as tentativas de suicídio e o suicídio agravos de notificação compulsória imediata em todo o território nacional, pontuando a necessidade de acionamento imediato da rede de atenção e proteção para a adoção de medidas adequadas a cada caso. Essa portaria foi revogada pela Portaria $n^{0}$ 204/201622, que acrescentou:

Art. $2^{\circ}$ Para fins de notificação compulsória de importância nacional serão considerados os seguintes conceitos: I - agravo: qualquer dano à integridade física ou mental do indivíduo, provocado por circunstâncias nocivas, tais como acidentes, intoxicações por substâncias químicas, abuso de drogas ou lesões decorrentes de violências interpessoais, como agressões e maus tratos, e lesão autoprovocada.

Portanto, esses dados revelam que a UMI necessita se adequar à legislação vigente, bem como investir em capacitações e educação permanente em relação ao preenchimento das Fichas de Notificação de Violência Autoprovocada, instrumentalizando os profissionais quanto a esse importante procedimento que é obrigatório ser realizado, pois a Notificação de Violências Interpessoal e Autoprovocada é uma das ações de vigilância em saúde, sendo um dos passos da linha de cuidado.

\section{DIFERENTES ACEPÇÕES SOBRE O FENÔMENO DO SUICIDIO}

A forma de morrer é algo cultural, então cada cultura e sociedade vivenciam a morte não intencional e o suicídio de formas diferentes e, historicamente, existe estigma e tabu em torno do tema do suicídio, conforme aponta a Associação Brasileira de Psiquiatria - ABP (2014): 
Durante séculos de nossa história, por razões religiosas, morais e culturais o suicídio foi considerado um grande "pecado", talvez o pior deles. Por esta razão, ainda temos medo e vergonha de falar abertamente sobre esse importante problema de saúde pública. ${ }^{23}$

Nesta categoria de análise, dois aspectos se destacaram a partir das verbalizações dos participantes: as características relacionadas ao risco e/ou tentativa de suicídio e o conceito de suicídio. No que concerne às características relacionadas ao risco e/ou tentativa de suicídio verbalizadas, os participantes relacionaram majoritariamente as tentativas a intoxicações medicamentosas, automutilações, transtornos mentais, violência contra a mulher e condições de vida e trabalho, conforme pode-se identificar nas narrativas de P1. P2 e P5:

"A questão do suicídio vejo que é uma questão muito importante e é uma questão de saúde pública porque cada vez mais as pessoas estão ficando depressivas, por vários fatores, financeiros, emocionais [...] Sempre recebo pessoas com tentativa de suicídio, pessoas que vêm e tomam medicação para poder se matar e não é uma vez, são várias vezes que acontece isso" (informação verbal participante P1).

"Ninguém quer morrer mesmo, as pessoas querem se livrar de uma dor que é muito grande, de um sofrimento que é insuportável" (informação verbal participante $\mathrm{P} 2$.)

"Aquela gestante de 12 anos, que foi violentada pelo padrasto, isso foi uma coisa bem chocante para mim [...] então daí quando ela chegou, tinha essa questão da ideação suicida e da mutilação e daí eu soube de toda a história, então o que eu procurei fazer foi amenizar, claro que você não vai conseguir sanar, jamais, mas você vai amenizar esse processo de trauma" (informação verbal participante P5)

Essas falas revelam que as características apontadas nas literaturas apresentadas neste estudo em relação ao comportamento suicida, vão de encontro com as características apontadas pelos participantes como comuns aos atendimentos na UMI. Como já apontado anteriormente, o suicídio é um fenômeno complexo e multicausal, ou seja, muitos fatores podem colaborar para que uma pessoa tenha um comportamento suicida, podendo derivar desde situações isoladas até um conjunto de fatores que levam o indivíduo a pensar em tirar sua própria vida.

Uma questão importante a considerar é que, em vários discursos dos participantes, ficou latente que a UMI não é um local para atender mulheres com risco e/ou tentativa de suicídio, colocando em xeque a legitimidade das demandas de saúde mental para os serviços da UMI, conforme pode-se observar na fala de P20:

\footnotetext{
"espera-se que uma mulher que acesse a maternidade é por outra razão, e não por transtorno mental, por sofrimento psíquico" (informação verbal participante P20).
}

Esses dados denunciam que os profissionais de saúde possuem lacunas na formação profissional em relação à organização do Sistema Único de Saúde - SUS, bem como em relação à Rede de Atenção Psicossocial - RAPS, que em 2011 foi instituida pela Portaria $n^{0} 3.088 / 2011^{23}$, que reordena o cuidado em saúde para pessoas com sofrimento ou transtorno mental, incluindo aquelas com necessidades decorrentes do uso de crack, álcool e outras drogas, ofertando o cuidado em saúde mental por todos os pontos da RAPS, que prevê a articulação desde as Unidades Básicas de Saúde - UBS, Centros de Convivência, Consultórios na Rua, Núcleo de Apoio à Saúde da Família - NASF até a Atenção Hospitalar e serviços de urgência e emergência (UPA 24h, SAMU 192).

Em relação ao conceito de suicídio, de maneira geral os participantes da pesquisa demonstraram ausência de conhecimento científico sobre o assunto e uma visão negativa sobre a mulher que é atendida por risco e/ou tentativa de suicídio, 
inclusive quando gestante. Tal concepção por parte dos profissionais evidencia a estigmatização dessas mulheres, além do tabu sobre o assunto, conforme as narrativas a seguir:

"Eu acho que poderia ter sempre educação continuada, não só nessa questão enquanto residência, mas enquanto equipe como um todo, porque as pessoas às vezes colocam seus valores nos atendimentos, então essas pacientes acabam sofrendo alguns estigmas" (informação verbal participante P3)

"Quando precisa internar devido a esse tipo de motivo, é internada junto com as outras gestantes e acaba colocando elas numa condição de vulnerabilidade [...] Já teve vários casos de tentativa de agressão aqui dentro do alojamento contra enfermeiro, contra médico, contra outros pacientes, contra o próprio neném recémnascido" (informação verbal participante P11)

"A dificuldade é que algumas entram em surto e acabam contaminando a paciente que está mais próxima. Então, por isso que é a importância (sic) delas terem um lugar mais reservado para elas" (informação verbal participante P15).

"Espera-se que uma mulher que acesse a maternidade é por outra razão, e não por transtorno mental, por sofrimento psíquico" (informação verbal participante P20).

As narrativas acima deixam claro ainda uma leitura rasa, pela perspectiva do senso comum sobre o assunto, relacionando o suicídio a problemas exclusivamente de ordem psiquiátrica, sugerindo o isolamento do convívio social por serem "perigosos", além disso esta é uma visão negativa sobre a mulher que acessa a maternidade por risco e/ou tentativa de suicídio, que se acentua quando ela é gestante. Essa forma de conceber indivíduos com questões de saúde mental é ultrapassada, e se persegue a sua superação desde a instituição do novo modelo de direcionamento da política de saúde mental no
Brasil, a partir da Reforma Psiquiátrica em meados dos anos 70:

No Brasil, o modelo de atenção à saúde mental, antes centrado em internações em hospitais psiquiátricos, foi redirecionado para serviços comunitários de saúde mental, de forma a se promover a garantia dos direitos das pessoas com transtornos mentais ${ }^{6}$.

A desgosto do significado que os participantes atribuem às mulheres com risco e/ou tentativa de suicídio, faz parte do compromisso ético dos mesmos, bem como dos órgãos públicos, proteger as pessoas que se encontram em situação de risco ou tentaram suicídio, reconhecendo-as e acolhendo-as em suas diferenças. Porém, outros estudos também apontam a falta de preparo, de conhecimentos e o preconceito dos profissionais de saúde para lidar com o paciente suicida. ${ }^{4}$

Evidenciou-se com esse estudo que a ausência de conhecimento científico sobre o suicídio é um dos pontos-chave para que não ocorram mudanças nos sentidos atribuídos ao comportamento suicida, bem como que é irrefutável a necessidade de instrumentalização dos profissionais para a lida com as mulheres com risco e/ou tentativa de suicídio no cotidiano da UMI, demanda esta também assinalada por outros estudos realizados nestes mesmos contextos. ${ }^{4}$ Promover a desestigmatização dessas pessoas também é uma estratégia de prevenção ao suicídio:

Um tabu, arraigado em nossa cultura, por séculos, não desaparece sem o esforço de todos nós. Tal tabu, assim como a dificuldade em buscar ajuda, a falta de conhecimento e de atenção sobre o assunto por parte dos profissionais de saúde e a ideia errônea de que o comportamento suicida não é um evento frequente condicionam barreiras para a prevenção. Lutar contra esse tabu é fundamental para que a prevenção seja bem-sucedida ${ }^{10}$. 


\section{CONSIDERAÇÕES FINAIS / CONCLUSÕES}

O adequado atendimento às mulheres com risco e/ou tentativa de suicídio na UMI é determinante para a recuperação e prevenção de que novas tentativas sejam cometidas. A atenção a esses casos pressupõe a mobilização e a organização dos serviços de saúde, a partir da construção de linhas de cuidado, da sensibilização dos profissionais e da desestigmatização do problema, da definição de fluxos e responsabilidades, articulados numa rede de cuidados e de proteção envolvendo tanto a saúde quanto recursos e estratégias intersetoriais.

Motivado por tal importância, o presente artigo investigou como ocorre o atendimento a pacientes com risco e/ou tentativa de suicídio na Unidade Materno-Infantil - UMI do Complexo Hospital de Clínicas - CHC/UFPR. Os dados mostraram que os procedimentos realizados (acolhimento, atendimento e encaminhamento) não diferem do perfil atendido em outros serviços de saúde semelhantes, conforme descreve a literatura. Destacaram-se o predomínio do público feminino, a intoxicação como método mais utilizado e que são múltiplos os fatores desencadeadores para o risco de suicídio.

Segundo o estudo, os participantes não atribuem legitimidade às demandas de atendimento desencadeadas pelo sofrimento psíquico, como as tentativas de suicídio, as demandas pertinentes para atendimento na UMI. Evidenciou-se que a UMI não dispõe de protocolos mínimos para atendimento às mulheres que chegam com risco e/ ou tentativa de suicídio. Foi possivel compreender os diferentes olhares sobre o fenômeno do suicídio, cuja explicação pode ter relação com a formação de cada profissional e o acesso a conhecimentos científicos sobre o assunto.

E por fim, sobre os procedimentos, foi possivel perceber que estes ocorrem baseados na avaliação feita pelos profissionais da equipe médica e multiprofissional. Contudo, ainda que haja um engajamento nesta tarefa, visando garantir um acolhimento ou a continuidade do tratamento do paciente na rede, foram assinaladas fragilidades no trabalho multiprofissional, como diferentes perspectivas de trabalho e uma lógica compartimentalizada de ação profissional.

Ainda que os resultados apresentados tenham legitimidade para as condições e contexto de pesquisa expostos, este estudo contribuiu para o debate sobre a necessidade de capacitação e educação permanente referente à temática do suicídio, bem como para o manejo das situações de tentativas de suicídio e sofrimento psíquico, aos profissionais de saúde que atuam nos contextos hospitalares. Vale ressaltar que, se os conteúdos teórico-práticos sobre saúde mental, com destaque para a discussão do comportamento suicida, fossem incluídos nos currículos dos cursos da área da Saúde, seria um avanço positivo para a atuação profissional nesse campo.

Reafirma-se a importância do trabalho multidisciplinar e multiprofissional para a oferta de cuidado integral, importante para a prevenção do suicídio e novas tentativas, bem como para promoção de qualidade de vida das mulheres com risco e/ou tentativa de suicídio atendidas na UMI e a necessidade de revisão da organização do trabalho, de promover capacitação aos profissionais e educação permanente em saúde referente à temática do suicídio e saúde mental, a fim de tornar o atendimento mais qualificado e menos atravessado por preconceitos e/ou julgamentos morais, já que os dados mostraram estigmas e tabus em torno dessas mulheres.

\section{REFERÊNCIAS}

1. World Health Organization. Global consultation on violence and health. Violence: a public health priority. Geneva: WHO; 1996 (document WHO/EHA/ SPI.POA.2).

2. Organización Panamericana de la Salud. Prevención del suicidio: un imperativo global [Internet]. Washington, DC: OPS; 2014 [citado 2017 Ago 6]. Disponivel em: http://apps.who.int/iris/bitstr eam/10665/136083/1/9789275318508_spa.pdf 
3. Vidal CEL, Gontijo ED. Tentativas de suicídio e o acolhimento nos serviços de urgência: a percepção de quem tenta. Cad Saúde Coletiva. 2013:21(2):108-14

4. Freitas APA, Borges LM. Do acolhimento ao encaminhamento: o atendimento às tentativas de suicídio nos contextos hospitalares. Estud psicol 2017:22(1):1678-4669.

5. Minayo MCS, Teixeira SMO, Martins JCO. Tédio enquanto circunstância potencializadora de tentativas de suicídio na velhice. Estud psicol. [Internet]. 2016 [citado 2018 Jan 5];21(1):3645. Disponivel em: http://www.scielo.br/scielo.php?pid=S1413294X2016000100036\&script=sci_abstract\&tlng=pt.

6. Ministério da Saúde, Secretaria de Vigilância em Saúde. Perfil epidemiológico das tentativas e óbitos por suicídio no Brasil e a rede de atenção à saúde. Boletim Epidemiológico [Internet]. 2017 Set [citado 2017 Set 30]:48(30):1-5. Disponível em: http://portalarquivos2.saude.gov.br/images/pdf/2017/setembro/21/2017025-Perfil-epidemiologico-das-tentativas-e-obitos-por-suicidiono-Brasil-e-a-rede-deatencao-a-saude.pdf.

7. Stefanello B, Furlanetto LM. Ideação suicida em pacientes internados em enfermarias de clínica médica: prevalência e sintomas depressivos associados. J bras psiquiatr [Internet]. 2012 [citado 2017 Out 20]:61(1):2-7. Disponivel em: http://www.scielo.br/pdf/ jbpsiq/v61n1/02.pdf.

8. Botega NJ. Crise suicida: avaliação e manejo. Porto Alegre: Artmed, 2015

9. Ministério da Saúde. Sistema de informação de agravos de notificação Informações de Saúde (TABNET). Epidemiológicas e Morbidade. 2010 - 2015 [homepage na internet]. Brasília: Ministério da Saúde; [citado 2017 Out 25]. Disponivel em: http://www2. datasus.gov.br/DATASUS/index.php?area=0203\&id=29892176\&V Obj=http://tabnet.datasus.gov.br/cgi/deftohtm.exe?sinannet/cnv/ Intox.

10. Associação Brasileira de Psiquiatria. Suicídio: informando para prevenir. Brasília: Conselho Federal de Medicina; 2014.

11. Bardin L. L'Analyse de contenu. Paris: Presses Universitaires de France; 1977.

12. Oates M. Suicide: the leading cause of maternal death. $\mathrm{Br} J$ Psychiatry. 2003;183, 279-281.

13. Barraclough B, Bunch J, Nelson B, Sainsbury P. A hundred cases of suicide: clinical aspects. Br J Psychiatry. 1974;125:355-73.

14.Alves, ACR. Reflexões sobre o processo de trabalho na saúde e suas implicações no cotidiano profissional do serviço social na realidade do Hospital Universitário de Juiz de Fora. [Internet]. Libertas 2005 Jan [citado 2017 Out 20];Spec 4-5:264-86. Disponivel em: https://libertas.ufjf.emnuvens.com.br/libertas/article/ view/1762.

15. Dias EC. Condições de trabalho e saúde dos médicos: uma questão negligenciada e um desafio para a Associação Nacional de Medicina do Trabalho. Rev Bras Med Trab. 2015;13(2):60-8.

16. Santana FR, Nakatani AYK, Freitas RAMM, Souza ACS, Bachion MM. Integralidade do cuidado: concepções e práticas de docentes de graduação em enfermagem do Estado de Goiás. Ciênc Saúde Colet. 2010:15(1):1653-64.

17. Brito-Silva K, Bezerra AFB, Tanaka OY. Direito à saúde e inte- gralidade: uma discussão sobre os desafios e caminhos para sua efetivação. Interface comun saúde educ. 2012 Abr;16(40):249-60.

18. Merhy EE, Franco TB. Trabalho em saúde. In: Pereira IB, Lima JCF. Dicionário da educação profissional em saúde. 2. ed. rev. ampl. Rio de Janeiro: EPSJV; 2008. p.427-32.

19. Sá NNB, Oliveira MGC, Mascarenhas MDM, Yokota RTC, Silva MMA, Malta DC. Atendimentos de emergência por tentativas de suicídio. [Internet] Rev med Minas Gerais. 2007 [citado 2019 Mai 8] :20(2):145-52. Disponivel em: http://www.rmmg.org/artigo/detalhes/307.

20. Brasil. Lei $n^{\circ}$ 6.259, de 30 de outubro de 1975. Dispõe sobre a organização das ações de Vigilância Epidemiológica, sobre o Programa Nacional de Imunizações, estabelece normas relativas à notificação compulsória de doenças, e dá outras providências. Diário Oficial da União, Poder Executivo, Brasília, DF, 31 Out 1975. Disponivel em: http://www.planalto.gov.br/ccivil_03/LEIS/L6259.htm.

21. Brasil, Ministério da Saúde. Portaria $n^{0}$ 1.271, de 06 de junho de 2014. Define a Lista Nacional de Notificação Compulsória de doenças, agravos e eventos de saúde pública nos serviços de saúde públicos e privados em todo o território nacional, nos termos do anexo, e dá outras providências. Brasília (DF); 2014. Saúde Legis - Sistema de Legislação da Saúde. 2014. Disponível em: http://bvsms.saude.gov.br/bvs/saudelegis/gm/2014/ prt1271_06_06_2014.html.

22. Brasil, Ministério da Saúde. Portaria n² 204, de 06 de fevereiro de 2016. Define a Lista Nacional de Notificação Compulsória de doenças, agravos e eventos de saúde pública nos serviços de saúde públicos e privados em todo o território nacional, nos termos do anexo, e dá outras providências. Saúde Legis - Sistema de Legislação da Saúde. 2016. Disponível em: http://bvsms.saude.gov. br/bvs/saudelegis/gm/2016/prt0204_17_02_2016.html.

23. Brasil, Ministério da Saúde. Portaria n 3.088, de 23 de dezembro de 2011. Institui a Rede de Atenção Psicossocial para pessoas com sofrimento ou transtorno mental e com necessidades decorrentes do uso de crack, álcool e outras drogas, no âmbito do Sistema Único de Saúde (SUS). Saúde Legis - Sistema de Legislação da Saúde. 2011. Disponivel em: http://bvsms.saude.gov.br/ bvs/saudelegis/gm/2011/prt3088_23_12_2011_rep.html.

RECEBIDO: 16/02/2019

ACEITO: 08/05/2019 